\title{
Impedance spectroscopy analysis of structural defects in sputtered $\mathrm{ZnO}$ films
}

\author{
J. Soares Costa ${ }^{a, b}$, M. Prestat ${ }^{a *}$, B. Tribollet ${ }^{c}$, B. Lescop ${ }^{b}$, S. Rioual ${ }^{b}$, L. Holzer ${ }^{d}$, \\ D. Thierry ${ }^{\mathrm{a}}$
}

${ }^{a}$ French Corrosion Institute, 220 rue Pierre Rivoalon, 29200 Brest, France.

${ }^{\mathrm{b}}$ Univ Brest, Lab-STICC, CNRS, UMR 6285, 29200 Brest, France.

c Sorbonne Université, CNRS, Laboratoire Interfaces et Systèmes Electrochimiques, LISE, 75005 Paris, France.

${ }^{\mathrm{d}}$ Institute of Computational Physics, Zurich University of Applied Sciences, Wildbachstrasse 21, 8400 Winterthur, Switzerland.

* corresponding author, e-mail: michel.prestat@institut-corrosion.fr

\begin{abstract}
The degradation of sputtered columnar $\mathrm{ZnO}$ layers under DC polarization was studied by electrochemical impedance spectroscopy and electron microscopy. It was found that the structure of the as-deposited $\mathrm{ZnO}$ film was dense at the nanoscale. An equivalent circuit model including a de Levie impedance accounted for the localized propagation of microscaled cracks towards the copper substrate. This generates a capacitance $\left(C_{Z n O}\right)$ that represents the crack surface area in contact with the electrolyte. $C_{Z n O}$ is small enough not to be obscured by the double layer capacitance at the top of the layers and increases with increasingly negative potential and time. These results were compared to nanoporous $\mathrm{ZnO}$ layers that behave differently and exhibit a large $C_{Z n O}$. The combination of in situ EIS analysis with the ex situ structural information provided by electron microscopy proved to be an efficient methodology to characterize very different microstructures of conductive coatings.
\end{abstract}

Keywords: impedance spectroscopy, microstructure, thin films, sputtering, zinc oxide.

\section{Introduction}

One of the most common strategies to protect metals from corrosion due to aggressive environments is to apply a coating on its surface. The coating acts as a physical barrier and may also provide galvanic protection in defect areas (as in the well-known case of galvanized steel). Eventually the protective properties decays. Thus, there is a prime interest in developing methodologies that enable to characterize, monitor and gain understanding in the degradation mechanism of those coatings. Regarding the decrease of the barrier properties, focus should be 
laid on the evolution of the microstructure of the layers and the development of defects, such as pores or cracks. Electrochemical impedance spectroscopy (EIS) can bring valuable insights in that matter provided that the equivalent circuits used for data analysis carry a truly physical meaning [1]. For instance, EIS has already been used by Barres et al. to investigate the porosity of silicon nitride $\left(\mathrm{SiN}_{\mathrm{x}}\right)$ thin films $(30-60 \mathrm{~nm})$ used in the glass industry as barrier layers [2]. In this work, high-resolution electron microscopy analysis revealed the presence of nanoscale pores $(0.5-2 \mathrm{~nm})$. The study distinguished "through-pores" in which the electrolyte could reach an underlying gold substrate and "non-through-pores" that crossed only a portion of $\mathrm{SiN}_{\mathrm{x}}$ layer. The impedance of the former was modelled as a pore resistance in series with a CPE with the distribution of resistivity of the latter being accounted for with the Young model $[3,4]$. The de Levie model has been developed for "ideal" electrodes exhibiting high electrical conductivity ("metallic electrodes") and parallel cylindrical pores with identical geometry to describe frequency dispersion using transmission lines [5]. Several studies showed that the de Levie impedance could be used to describe analytically more complex systems with pores of various geometry, length and radius [6-9]. Barcia et al. utilized the de Levie impedance to characterize macroporous red rust of cast iron in Evian mineral water [9].

In the present work, EIS measurements were performed to gain more understanding about the structural degradation of "model" $\mathrm{ZnO}$ layers in alkaline electrolyte. The results of columnar $\mathrm{ZnO}$ layers, that are compact at the nanoscale, are compared with those of nano-granular $\mathrm{ZnO}$ exhibiting a nanoporous structure. The $\mathrm{ZnO}$ electrodes were prepared by radio-frequency magnetron sputtering. This deposition technique conveniently enables to prepare layers of various nanostructures by modifying experimental parameters, such as type of target, power, substrate temperature, and fluxes of reactive gases [10-13]. The experimental impedance data was fitted with two equivalent circuit models, one accounting for a fully dense $\mathrm{ZnO}$ layer and the other describing the penetration of the electrolyte in the defects of the films. The global in situ information provided by EIS was completed by the local ex situ structural data at the nanoscale and microscale obtained with top-view and cross-sectional electron microscopy images. In the past years, some reports have demonstrated the benefits of cross-sectional analysis (with focus ion beam or scanning transmission electron microscopy) in order to gain valuable insight on the effect of the microstructure on the protective properties of $\mathrm{ZnO}$ [14-19]. A negative polarization was applied to the sputtered $\mathrm{ZnO}$ electrodes since the present study was carried out in the context of the investigation of the cathodic properties of $\mathrm{ZnO}$ [14-16,21]. The cathodic activity of $\mathrm{ZnO}$ is still debated in the literature [14-16, 20-23], as reminded by 
Cole in a recent review on zinc corrosion [24]. A previous work of our group presented the electrokinetic properties of sputtered $\mathrm{ZnO}$ layers towards oxygen reduction [16].

\section{Experimental}

\section{Synthesis of the $\mathrm{ZnO}$ layers}

$\mathrm{ZnO}$ films were deposited on copper substrates by radio-frequency magnetron sputtering (Univex 350, Oerlikon). Copper cylinder substrates (5 $\mathrm{mm}$ diameter, $4 \mathrm{~mm}$ height) were micromachined from commercially available rods (purity $>99.95 \%$, GoodFellow) to fit the rotating disk electrode setup. After machining, the substrates were grinded with SiC paper (P2500 and P4000 for $60 \mathrm{~s}$ each) using water as a lubricant. The finishing of the surface was done with a polishing cloth and polycrystalline diamond suspensions ( $3 \mu \mathrm{m}$ and $1 \mu \mathrm{m}$, each for $180 \mathrm{~s})$. The substrates were then ultrasonically cleaned in ethanol, rinsed in deionized water and air-dried. For sputtering deposition of the columnar $\mathrm{ZnO}$ films, the working chamber was vacuumed to reach a base pressure of 3-5 $10^{-7}$ mbar. The substrates were fixed at a distance of ca. $10 \mathrm{~cm}$ parallel to the $\mathrm{ZnO}$ target surface (diameter: 3 inches). Films were deposited for 90 minutes with a mixture of reactive gas (Argon: $\mathrm{O}_{2}, 15: 10 \mathrm{sccm}$ ) inside the chamber. The gas purities were $99.9996 \%$ for Argon and $99.9995 \%$ for $\mathrm{O}_{2}$. Pre-sputtering was carried out for 30 min to clean and equilibrate the target surface prior to deposition. The same conditions were used for pre-sputtering and sputtering, except deposition time. During deposition, the total pressure was kept at $2 \times 10^{-2}$ mbar. The input power at the target was $75 \mathrm{~W}$. The resulting layers were ca. 300 nm thick.

For the synthesis of nano-granular $\mathrm{ZnO}$ layers, a zinc target (diameter: 3 inches) was used. The mixture of argon and oxygen gases was $\mathrm{Ar}: \mathrm{O}_{2} 20: 3 \mathrm{sccm}$. The total pressure was $1.7 \times 10^{-2} \mathrm{mbar}$ and the input power $250 \mathrm{~W}$. The layers had a thickness of ca. $800 \mathrm{~nm}$ for a deposition time of $5 \mathrm{~min}$.

\section{Characterization}

$\mathrm{X}$-ray diffraction (XRD) was carried out to evidence the crystalline structure of the $\mathrm{ZnO}$ layers using PANalytical Empyrean apparatus with CuK radiation (1.5408 ̊).

High-angle annular dark-field scanning transmission electron microscopy (HAADF-STEM) imaging was used to characterize the internal structure of the as-deposited layers at the nanoscale and notably its degree of compacity based on Z-contrast. For this purpose, TEMlamellas representing cross-sections of the $\mathrm{ZnO}$ layers were prepared with the focused ion beam 
(FIB) technique. The ZnO layers were then investigated with an analytical TEM (FEI Talos $\mathrm{F} 200 \mathrm{X})$ at $200 \mathrm{kV}$.

Top-view imaging was performed by conventional scanning electron microscopy (SEM, SU3500, Hitachi) to evaluate the aspect of surface of the layers at the microscale. The $\mathrm{Zn}: \mathrm{O}$ ratio was determined by energy dispersive X-ray spectroscopy (EDX, UltraDry EDX detector and Thermo Scientific software NSS 312) with an acceleration voltage of $5 \mathrm{kV}$.

\section{Electrochemical measurements}

The electrochemical experiments were conducted at room temperature in aerated $\mathrm{KOH}$ solutions at $\mathrm{pH}=10+/-0.1$ with $\mathrm{KCl} 0.2 \mathrm{M}$ as supporting electrolyte. EIS measurements were carried out under controlled hydrodynamic conditions using the rotating disk electrode (RDE) technique (Pine Research Instrumentation, Durham, NC, USA). The counter-electrode was a large titanium-based metallic grid placed below the working electrode. The reference electrode was a mercury/mercury oxide electrode $(\mathrm{Hg}-\mathrm{HgO}, \mathrm{KOH} 1 \mathrm{M})$. The three-electrode setup was controlled by a Gamry Reference 600 potentiostat. The applied frequency domain ranged from

$10^{5} \mathrm{~Hz}$ to $1 \mathrm{~Hz}$ with 10 points per decade. The sinusoidal perturbation was $10 \mathrm{mV}$. Data fitting was carried out using non-commercial software developed at the Laboratoire Interfaces et Systèmes Électrochimiques (LISE), Paris, France.

In preliminary measurements in air between two copper electrodes (not shown here), both types of $\mathrm{ZnO}$ exhibited sufficiently high electrical conductivity (around $10^{-2} \Omega^{-1} \mathrm{~cm}^{-1}$ ). This enabled to neglect the ohmic drop within the $\mathrm{ZnO}$ layers during $\mathrm{DC}$ polarization. In potentiodynamic voltammetry experiments, the cathodic polarization curves were recorded with a scan rate of 1 $\mathrm{mV} / \mathrm{s}$.

\section{Results and discussion}

Figure 1 shows the $\mathrm{XRD}$ patterns of the $\mathrm{ZnO}$ thin films. For the layers prepared with the zinc oxide target, the presence of a strong (002) peak at $34^{\circ}$ indicates a clear preferred orientation along the c-axis of the wurtzite structure (although a minor diffraction peak at $62.7^{\circ}$ associated with (013) planes is observed). This finding is in good agreement with the results reported in the literature using similar conditions as in the present work [25-29]. In contrast, the diffractogram of the samples prepared with the zinc target exhibit multiple peaks, such as (002), (010) and (011), which characterizes the absence of preferred orientation.

The atomic composition of the films was measured by EDX (not shown here) confirming the deposition of $\mathrm{ZnO}$ with a $\mathrm{Zn}: \mathrm{O}$ ratio close to $1: 1$ for both types of films. 
Electron microscopy analysis provides relevant ex situ microstructural information on the $\mathrm{ZnO}$ layers at the microscale and the nanoscale. Analysis of HAADF-STEM images allows determining porosity (that appears in black contrast) at the nanoscale $[2,30,31]$. The columnar $\mathrm{ZnO}$ (prepared with $\mathrm{ZnO}$ target) is evidenced to have a very compact structure (Figure 2a).

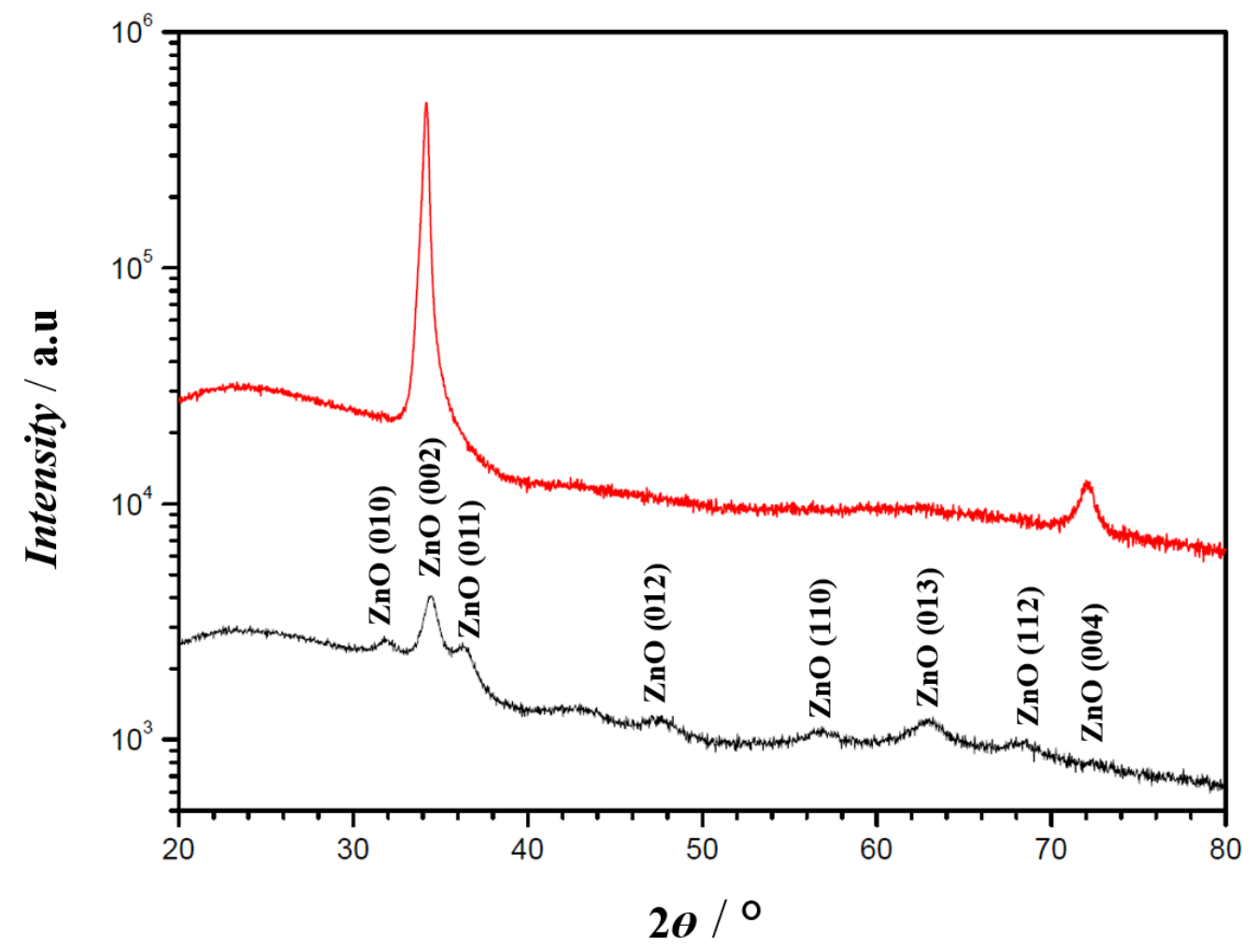

Figure 1: $\mathrm{XRD}$ spectra of the as-deposited $\mathrm{ZnO}$ thin films: columnar $\mathrm{ZnO}$ prepared with $\mathrm{ZnO}$ target (red curve) and nano-granular $\mathrm{ZnO}$ deposited using a $\mathrm{Zn}$ target (black curve).

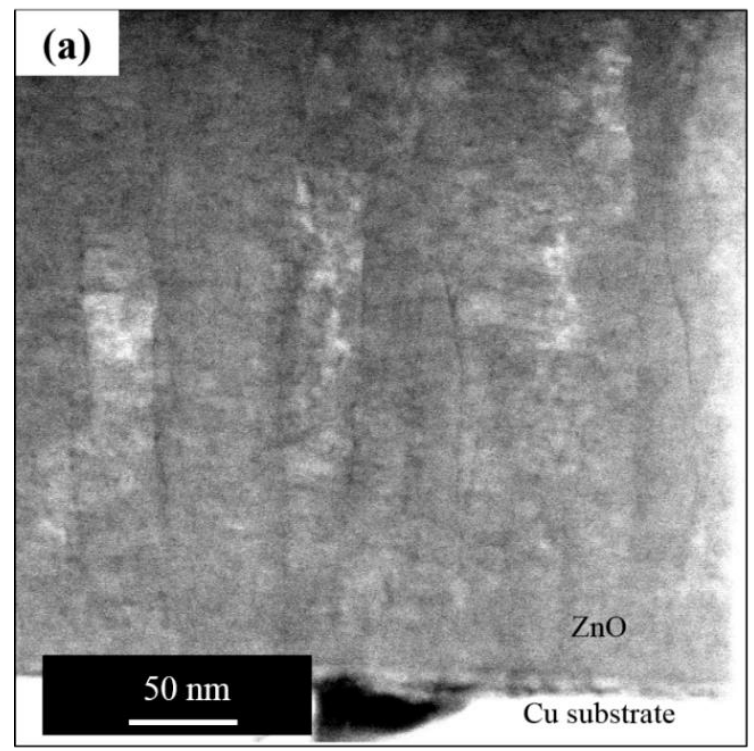

(b)

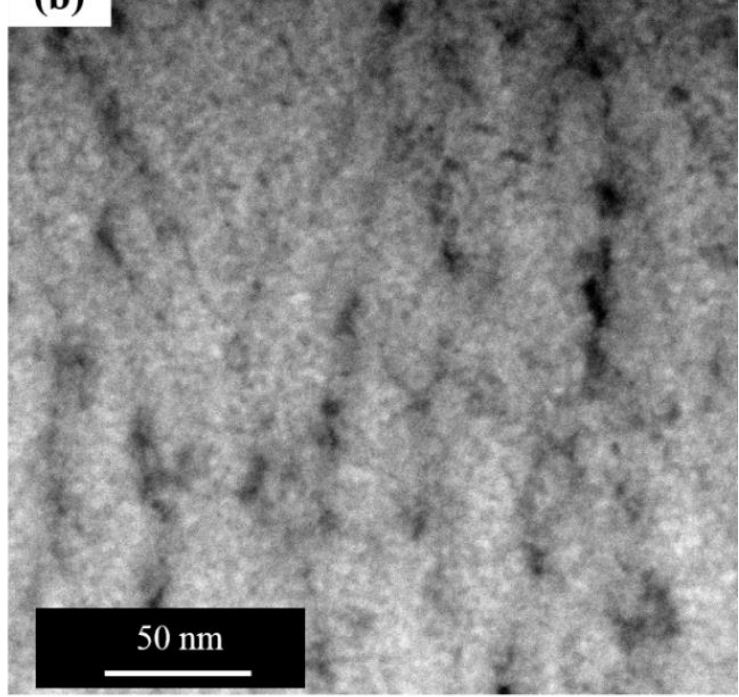


Figure 2: HAADF-STEM analysis of the as-deposited $\mathrm{ZnO}$ layers: (a) columnar $\mathrm{ZnO}$ and (b) nanogranular $\mathrm{ZnO}$.

Only very thin vertical black lines between the columns were detected. They are interpreted either as grain boundaries or as extremely narrow pores that are very unlikely to let the electrolyte go through in view of their aspect ratio. The width of the columns is ca. $30-100 \mathrm{~nm}$. Figure $2 \mathrm{~b}$ demonstrates that the nano-granular $\mathrm{ZnO}$ (prepared with $\mathrm{Zn}$ target) has a nanoporous structure. The HAADF-STEM observations are therefore consistent with the XRD findings of Figure 1.
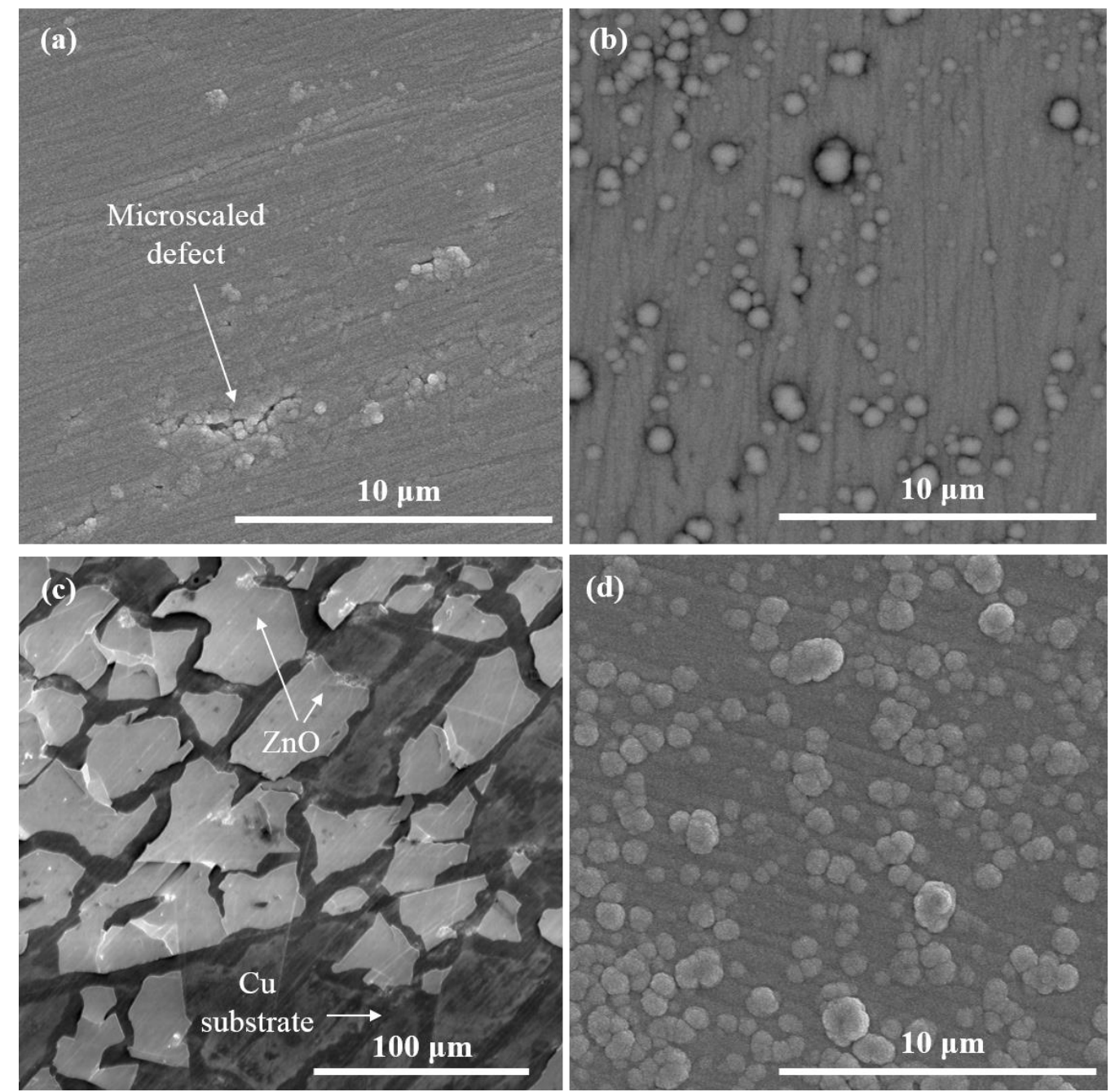

Figure 3: Top-view SEM micrographs of the two types of $\mathrm{ZnO}$ layers in the as-deposited state and after polarization at $-0.7 \mathrm{~V}$. (a) as-deposited columnar $\mathrm{ZnO}$; (b) as-deposited nano-granular $\mathrm{ZnO}$; (c) columnar $\mathrm{ZnO}$ after polarization; (d) nano-granular $\mathrm{ZnO}$ after polarization. 
Figure 3 shows the surface of the $\mathrm{ZnO}$ films using conventional SEM, providing therefore relevant morphological information at the microscale. The micrographs were taken in the asdeposited state and after cathodic polarization at $-0.7 \mathrm{~V}$. The open circuit potential (OCP) was ca. -0.05 to $-0.1 \mathrm{~V}$, depending on the sample. For the columnar $\mathrm{ZnO}$, one can notice the presence of some micro-scaled defects in the otherwise dense microstructure (Figure 3a). After polarization at $-0.7 \mathrm{~V}$, the films are cracked and partially delaminated (Figure $3 \mathrm{c}$ ). The degree of damage after polarization varied from one sample to another. Cracks were systematically present but their number varied. This mechanical instability does not affect the nano-granular $\mathrm{ZnO}$ that only becomes rougher under polarization by developing some nodule-like features at its surface (Figure $3 b$ and $3 c$ ).

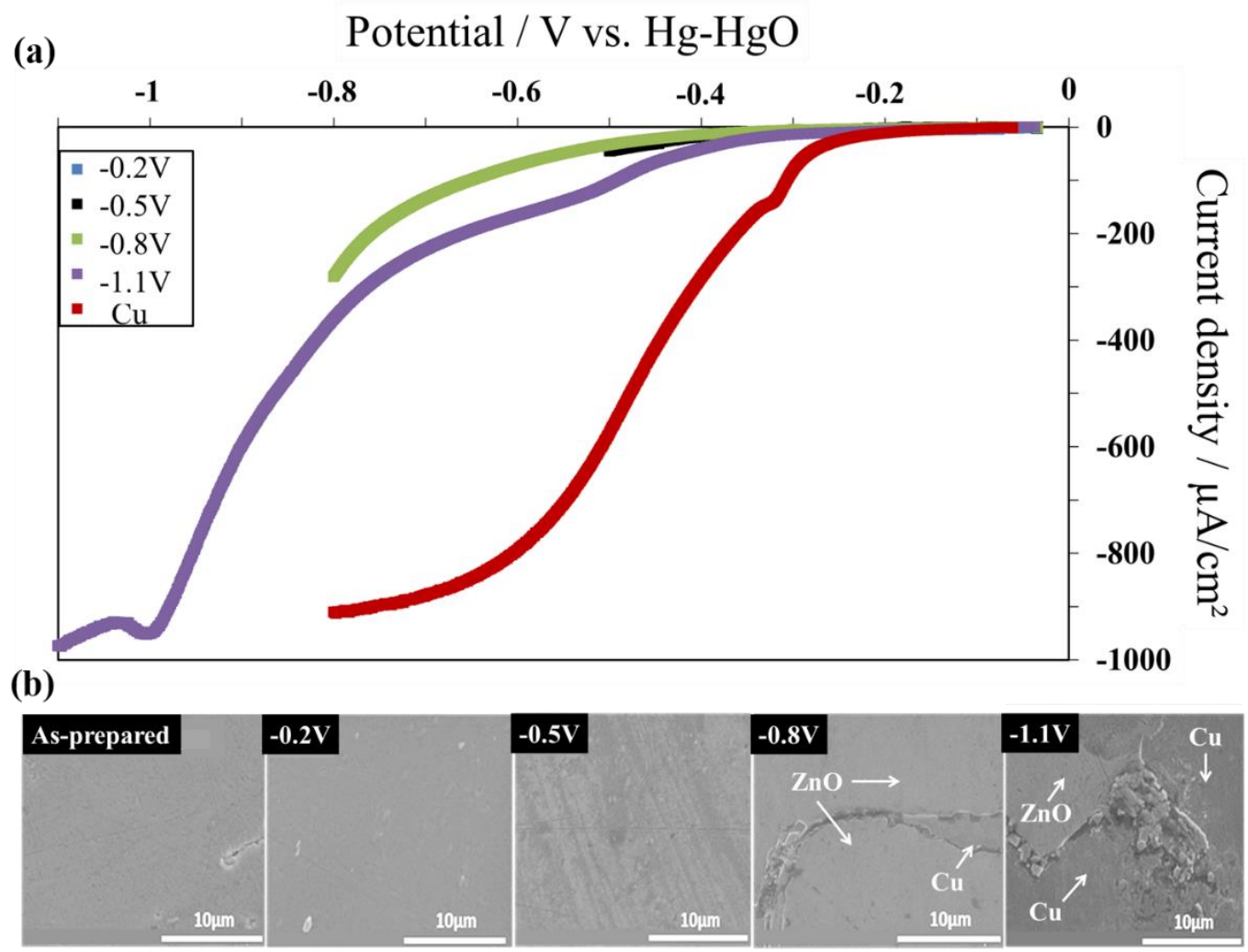

Figure 4: DC characterization of two typical columnar ZnO samples: (a) Polarization curves between open-circuit potential (ca. $-0.05 \mathrm{~V}$ ) and various increasingly negative potentials: $-0.2 \mathrm{~V},-0.5 \mathrm{~V},-0.8 \mathrm{~V}$ and $-1.1 \mathrm{~V}$ (in this order). The polarization curve of bare copper (red curve) is also displayed for comparison. For all curves, the disk potential scan rate was $1 \mathrm{mV} \mathrm{s}^{-1}$ and the rotation rate was $1000 \mathrm{rpm}$. (b) SEM top-view micrographs recorded after each polarization. 
The typical DC behaviour of a columnar $\mathrm{ZnO}$ film is displayed in Figure 4. Figure 4a shows the polarization curves of a single $\mathrm{ZnO}$ layer recorded between open circuit potential and various end-potentials: $-0.2 \mathrm{~V},-0.5 \mathrm{~V},-0.8 \mathrm{~V}$ and $-1.1 \mathrm{~V}$, in this order. After each polarization, the $\mathrm{ZnO}$ film surface was investigated by SEM to search for degradation evidence (Fig. 4b). The curve of the copper substrate is also provided for comparison. A significant difference of activity between $\mathrm{ZnO}$ and copper is observed. At $-0.6 \mathrm{~V}$, the current density obtained for $\mathrm{ZnO}$ was ca. $-100 \mu \mathrm{A} / \mathrm{cm}^{2}$ while that of copper was ca. $-900 \mu \mathrm{A} / \mathrm{cm}^{2}$. This result shows that this type of $\mathrm{ZnO}$ is not an efficient ORR electrocatalyst. Furthermore the electrochemical behaviour of columnar $\mathrm{ZnO}$ was found to be unstable.

When the potential scan was stopped at $-0.2 \mathrm{~V}$ and $-0.5 \mathrm{~V}$, the polarization curves remained unchanged. Though a slight roughening of the surface is visible at $-0.5 \mathrm{~V}$ (Figure 4b), no significant damage, such as cracks, was detected. After the polarization till $-0.8 \mathrm{~V}$, large cracks were visible, leading in some cases to local delamination of the $\mathrm{ZnO}$ films. Typically, during potentiodynamic experiments, partial rupture of the film is observed at potential around -0.6 $\mathrm{V}$, though the rupture potential and the degree of damage might vary from one sample to another. At the beginning of the fourth experiment (polarization till $-1.1 \mathrm{~V}$ ), the film was already damaged and exposed the underlying copper substrate. This explains the higher current density in the polarization curve. The consequence of the relatively fast mechanical instability of the columnar $\mathrm{ZnO}$ films is that in-depth investigation of the oxygen reduction mechanism and kinetics using collection-based techniques, such as rotating-ring disk electrode (RRDE) or double channel flow cell [22,32,33], was not possible. A recent RRDE study of ORR on the more stable nano-granular $\mathrm{ZnO}$ is available elsewhere [16].

DC polarization curves coupled with post-mortem top-view SEM analysis evidence the potential dependence of the degradation. However, this approach does not provide significant insights on the initial stages of the degradation. Hence EIS experiments were also performed to gain more understanding on this process. Note that, in what follows, resistance, impedance and capacitance values are expressed relative to the geometrical surface area of the disk electrode (i.e. in $\Omega \mathrm{cm}^{2}$ and in $\mu \mathrm{F} / \mathrm{cm}^{2}$ ). Figure 5 shows the experimental impedance, $Z_{\text {exp }}$, of the columnar $\mathrm{ZnO}$ (real part: $Z_{r}$; imaginary part: $Z_{i}$ ).

It has been demonstrated in the literature that, in the "classical" Bode plots (as-recorded, without correction), the high frequency data might be obscured by the electrolyte resistance, $R_{e}$, which can be misleading for data interpretation [34-36]. In the present study, the $R_{e}$ value was obtained by graphical extrapolation of the Nyquist plot onto the real axis at high 
frequencies (Figs. 5a and 5b). The effect of the $R_{e}$ correction on the Bode plots is shown in Figs. $5 \mathrm{c}$ and $5 \mathrm{~d}$.
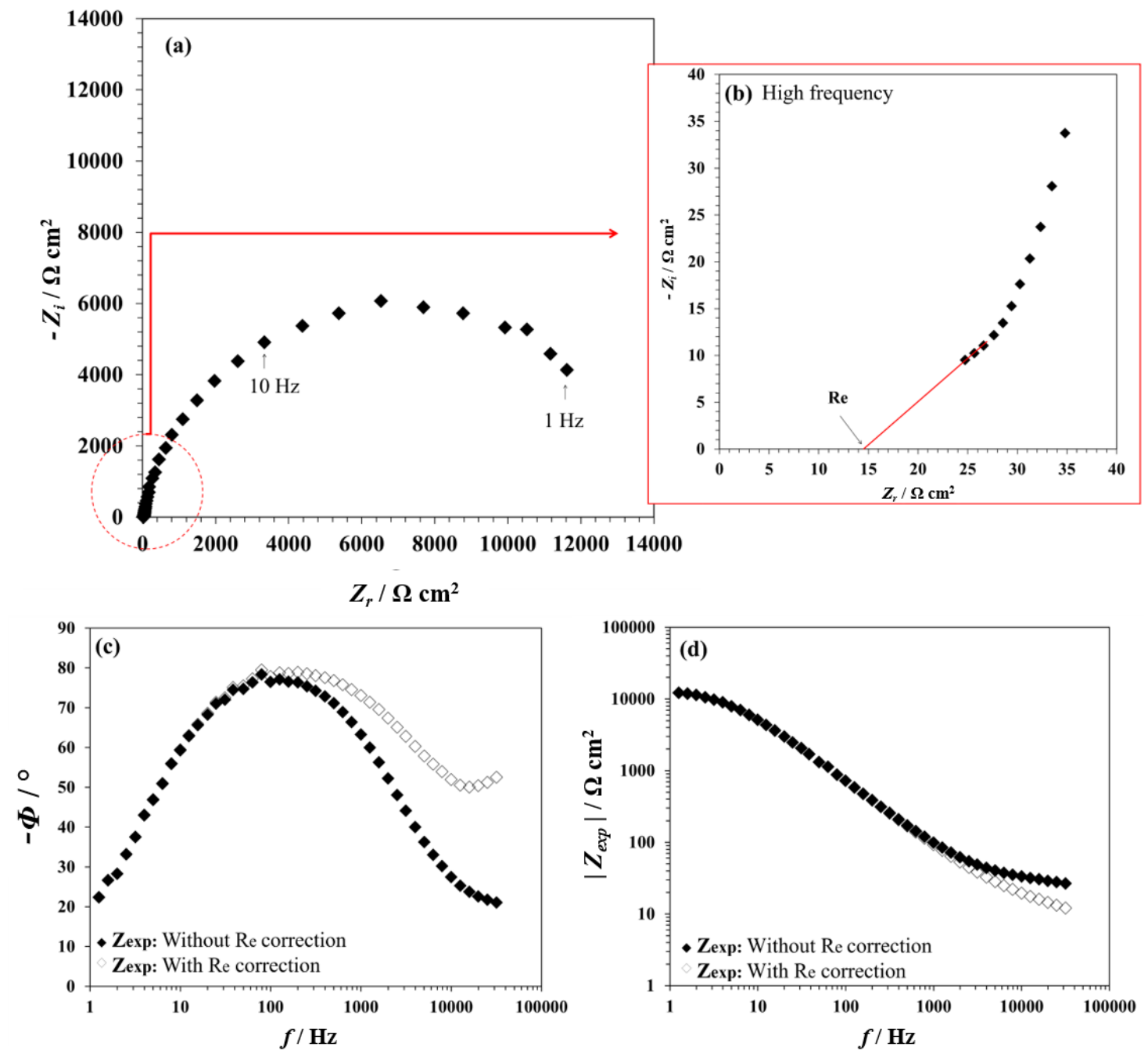

Figure 5: Typical EIS diagrams for columnar $\mathrm{ZnO}$ (recorded at $-0.4 \mathrm{~V}$ ). (a) Nyquist plot with (b) zoom in high frequency to determine the electrolyte resistance $\left(R_{e}\right)$. Bode plots (without and with $\mathrm{R}_{\mathrm{e}}$ correction): (c) phase curve and (d) modulus curve.

Two equivalent circuit models were tested for describing the AC behaviour of the $\mathrm{ZnO}$ films under cathodic polarization (Figure 6). Model 1 describes a fully dense $\mathrm{ZnO}$ layer (Figure 6a) whereas Model 2 includes a de Levie impedance (hereafter denoted $Z_{Z n O}$ ) to account for the penetration of the electrolyte in the structural defects of the films, such as cracks and pores (Figure 6b). The components of the models are described in the next lines. 
$R_{e}$ is the electrolyte resistance between the $\mathrm{ZnO}$ film and the reference electrode. The faradaic impedance, $Z_{f}$, is simplified to a cathodic charge transfer resistance, $R_{c t}$. An anodic contribution is not necessary as the EIS measurements are carried out at negative overpotentials "far" from the OCP. Thus:

$Z_{f}=R_{c t}$
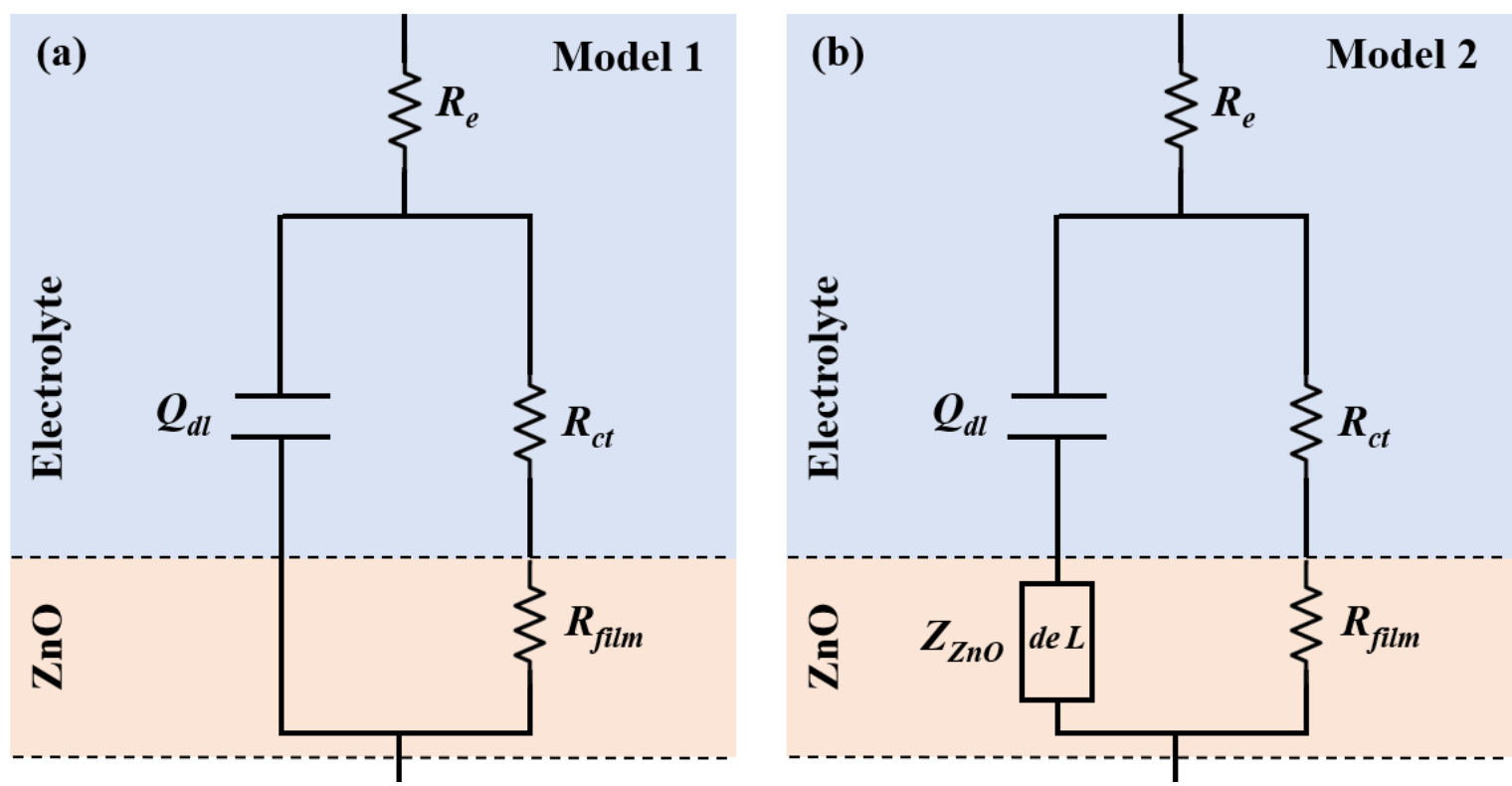

Figure 6: Equivalent circuit models: (a) Model 1 describing a fully dense $\mathrm{ZnO}$ layer (without de Levie impedance); (b) Model 2 with de Levie impedance accounting for a $\mathrm{ZnO}$ layer with microstructural defects (cracks, porosity).

$R_{f i l m}$ is the electronic resistance of the film. As mentioned above, the resistivity $\rho$ was evaluated to be ca. $10^{2} \Omega \mathrm{cm}$ for both types of $\mathrm{ZnO}$. This low resistivity value suggests that the impedance of the $\mathrm{ZnO}$ layers cannot be described by models accounting for distribution of resistivity within the films (such as the Young model [3] or the power law model [4]). $R_{f i l m}$ equals the product $\rho L$ (with $L$ being the layer thickness of ca. $300 \mathrm{~nm}$ or $800 \mathrm{~nm}$ ) and is around $\sim 3-8$ $10^{-3} \Omega \mathrm{cm}^{2} . R_{\text {film }}$ is much smaller than $R_{c t}$ and is therefore neglected in the fitting process for both Model 1 and Model 2.

The double layer capacitance at the $\mathrm{ZnO} /$ electrolyte interface is represented by a constant phase element (CPE) whose impedance, $Z_{d l}$, is: 
$Z_{d l}=\frac{1}{Q_{d l}(j \omega)^{\alpha}}$

with $\omega$ being the angular frequency (expressed in rad $\mathrm{s}^{-1}$ ). The frequency, $f$ (expressed in $\mathrm{Hz}$ ), equals $f / 2 \pi$. $Q_{d l}$ and $\alpha$ the frequency-independent CPE parameters.

The de Levie impedance representing the defects (pores, cracks) in the $\mathrm{ZnO}$ layers is expressed as:

$Z_{Z n O}=\sqrt{\frac{R_{0} Z_{0}}{n^{2}}} \operatorname{coth} \sqrt{\frac{R_{1}}{Z_{0}}}$

with $R_{0}$ being the electrolyte resistance per unit of pore length (in $\Omega \mathrm{cm}^{-1}$ ). $n$ is the number of pores per $\mathrm{cm}^{2} . R_{1}$ is product $l^{2} R_{0}$, where $l$ is the length of the cylindrical pore of the "ideal" electrode of de Levie [5]. In the present model, that does not aim at evaluating precisely the pores (cracks) geometry, only $R_{1}$ is used as a fitting parameter. $Z_{0}$ is the interfacial impedance per unit length of pore (expressed in $\Omega \mathrm{cm}$ ). Here, one assumes no charge transfer reaction in the pores and, $Z_{0}$ is simply described in Eq. (4) by a CPE corresponding to the double layer capacitance along the pore wall whose parameters are $Q_{\text {pore }}$ and $\beta$.

$Z_{0}=\frac{1}{Q_{\text {pore }}(j \omega)^{\beta}}$

At low frequencies, $\sqrt{\frac{R_{l}}{Z_{0}}}$ is small, hence:

$\operatorname{coth} \sqrt{\frac{R_{1}}{Z_{0}}}=\sqrt{\frac{Z_{0}}{R_{1}}}$

By combining Eqs. (3), (4) and (5), one obtains:

$Z_{Z n O}=\sqrt{\frac{R_{0}}{n^{2} R_{l}}} Z_{0}=\sqrt{\frac{R_{0}}{n^{2} R_{1}}} \frac{1}{Q_{\text {pore }}(j \omega)^{\beta}}=\frac{1}{Q_{Z n O}(j \omega)^{\beta}}$ 
with

$Q_{Z n O}=Q_{\text {pore }} \sqrt{\frac{n^{2} R_{1}}{R_{0}}}$

At high frequencies, $\sqrt{\frac{R_{l}}{Z_{0}}}$ is large, thus:

$\operatorname{coth} \sqrt{\frac{R_{1}}{Z_{0}}}=1$

By combining Eqs. (3), (4) and (8), one gets:

$Z_{Z n O}=\sqrt{\frac{R_{0} Z_{0}}{n^{2}}}=\sqrt{\frac{R_{0}}{n^{2}} \frac{1}{Q_{\text {pore }}(j \omega)^{\beta}}}=\sqrt{\frac{1}{Q_{l}(j \omega)^{\beta}}}$

with

$Q_{1}=Q_{\text {pore }} \frac{n^{2}}{R_{0}}$

Once the values of $Q_{d l}$ and $Q_{Z n O}$ are known, the capacitances $C_{d l}$ and $C_{Z n O}$ can be obtained with the Brug formula [37]:

$C_{d l}=Q_{d l}^{1 / \alpha} R_{e}^{(1-\alpha) / \alpha}$

$C_{\mathrm{ZnO}}=Q_{\mathrm{ZnO}}{ }^{1 / \beta} R_{e}(1-\beta) / \beta$

$Q_{\mathrm{ZnO}}$ (and therefore $C_{\mathrm{ZnO}}$ ) can be assessed only at low frequencies. At high frequencies, $Q_{\text {pore }}$ and $R_{0} / n^{2}$ cannot be determined independently of one another. Only their ratio, $Q_{1}$, can be extracted from the fitting (Eqs. (9) and (10)).

Depending on the applied model, the total simulated impedance, $Z_{s i m}$, has the following expression: 
Model 1: $Z_{\text {sim }}=\frac{1}{\frac{1}{R_{c t}}+\frac{1}{Z_{d l}}}+R_{e}$

In that case, the variables in the fitting process between $Z_{\exp }$ and $Z_{s i m}$ are $R_{c t}, Q_{d l}$ and $\alpha$.

In Model 2, the impedance of the electrode/electrolyte double layer $\left(Z_{d l}\right)$ and that of the $\mathrm{ZnO}$ defects $\left(Z_{Z n O}\right)$ are in series. Two cases are considered below: $C_{Z n O}<<C_{d l}$ and $C_{Z n O} \gg>C_{d l}$.

Model 2 with $C_{Z n O}<<C_{d l}$ : Here, the double layer physically exists, but its impedance, $Z_{d l}$, is small compared to that of $Z_{Z n O}\left(Z_{d l}<<Z_{Z n O}\right)$ and can be neglected. This leads to:

$Z_{\text {sim }}=\frac{1}{\frac{1}{R_{c t}}+\frac{1}{Z_{Z n O}}}+R_{e}$

Thus, in the fitting process, the variables are $R_{c t}, R_{0} / n^{2}, R_{l}, Q_{\text {pore }}$ and $\beta$ (Equation (6)). $Q_{Z n O}$ is calculated from the values of $R_{0} / n^{2}, R_{l}$ and $Q_{p o r e}$ using Equation (7).

Model 2 with $C_{Z n O} \gg C_{d l}$ : In this case, at low frequencies, $Z_{Z n O}<<Z_{d l}$. At the highest frequencies, $Z_{Z n O}$ cannot be neglected and is given by Equation (9). $Z_{s i m}$ is thus expressed as:

$Z_{\text {sim }}=\frac{1}{\frac{1}{R_{c t}}+\frac{1}{Z_{Z n O}+Z_{d l}}}+R_{e}$

$R_{c t}, Q_{l}, \beta, Q_{d l}$ and $\alpha$ are the variables of the fitting process.

A comparison between the experimental data of the columnar $\mathrm{ZnO}$ recorded at $-0.4 \mathrm{~V}$ (Figure 5) and the simulated impedance derived from Model 1 (Eq. (13)) is given in Figure 7. The results of the fitting process are listed in Table 1. Model 1 works well at low frequencies (below $38 \mathrm{~Hz}$ ) only. $C_{d l}$ is found to be around $1 \mu \mathrm{F} \mathrm{cm}^{-2}$, which is very small compared to the typical double layer capacitance values (around 10-100 $\mu \mathrm{F} \mathrm{cm}^{-2}$ ). Similar low values were obtained for all applied potentials between $-0.3 \mathrm{~V}$ and $-0.5 \mathrm{~V}$ (not shown here). Furthermore, at high frequencies, the model does not account for the decrease of the phase (Fig. 7a) and the change 
of slope of the modulus curve (Fig. 7b). Hence Model 1 is not considered as suitable for the columnar $\mathrm{ZnO}$ electrodes.
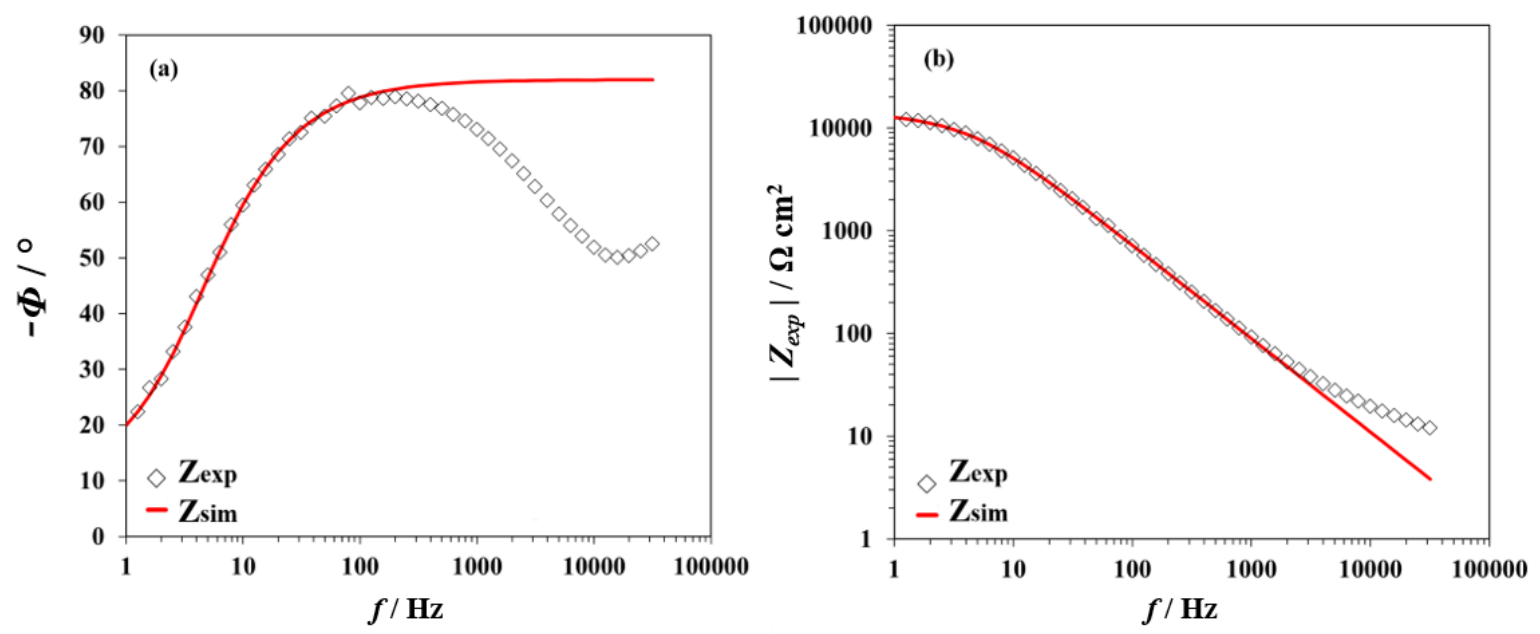

Figure 7: Fitting results for the columnar $\mathrm{ZnO}$ using Model 1. Re-corrected Bode plots obtained at $0.4 \mathrm{~V}$ : (a) phase and (b) modulus. The open symbols represent the experimental data $\left(Z_{\text {exp }}\right)$. The red line represented the simulated data $\left(Z_{\text {sim }}\right)$.

Table 1: Results of the fitting process for the columnar $\mathrm{ZnO}$ layers (Fig. 7) using Model 1.

\begin{tabular}{|c|c|c|c|}
\hline $\begin{array}{c}R_{c t} \\
\left(\Omega \mathrm{cm}^{2}\right)\end{array}$ & $\begin{array}{c}Q \\
\left(\Omega^{-1} \mathrm{~cm}^{-2} \mathrm{~s}^{\alpha}\right)\end{array}$ & $\alpha$ & $\begin{array}{c}C_{d l} \\
\left(\mu \mathrm{F} \mathrm{cm}^{-2}\right)\end{array}$ \\
\hline $1.410^{+4}$ & $4.410^{-6}$ & 0.89 & 1.4 \\
\hline
\end{tabular}

In contrast, the fitting of the experimental data works much better using Model 2 with $C_{Z n O} \ll C_{d l}$ (Eq. (14)), as shown in Figure 8. $Z_{\text {exp }}$ was recorded at $-0.4 \mathrm{~V}$ and $-0.5 \mathrm{~V}$. The corresponding fitting parameters are listed in Table $2 . Z_{\text {exp }}$ is very well described by $Z_{\text {sim }}$ at all frequencies. At low frequencies, the values of the phase $\left(82^{\circ}\right.$ at $-0.4 \mathrm{~V}$ and $76.8^{\circ}$ at $\left.-0.5 \mathrm{~V}\right)$ correspond to the limiting phase of the CPE of Eq. (6) and are equal to $\beta \times 90^{\circ}$. At high frequencies, the phase values $\left(41^{\circ}\right.$ at $-0.4 \mathrm{~V}$ and $38.4^{\circ}$ at $-0.5 \mathrm{~V}$ ) correspond to the half of the limiting phase of the CPE appearing in the square root function in Eq. (9). Similarly, the slope of the modulus Bode plot is $-\beta$ at low frequencies (derived from Eq. 6) and $-\beta / 2$ at high frequencies (derived from Eq. 9). 

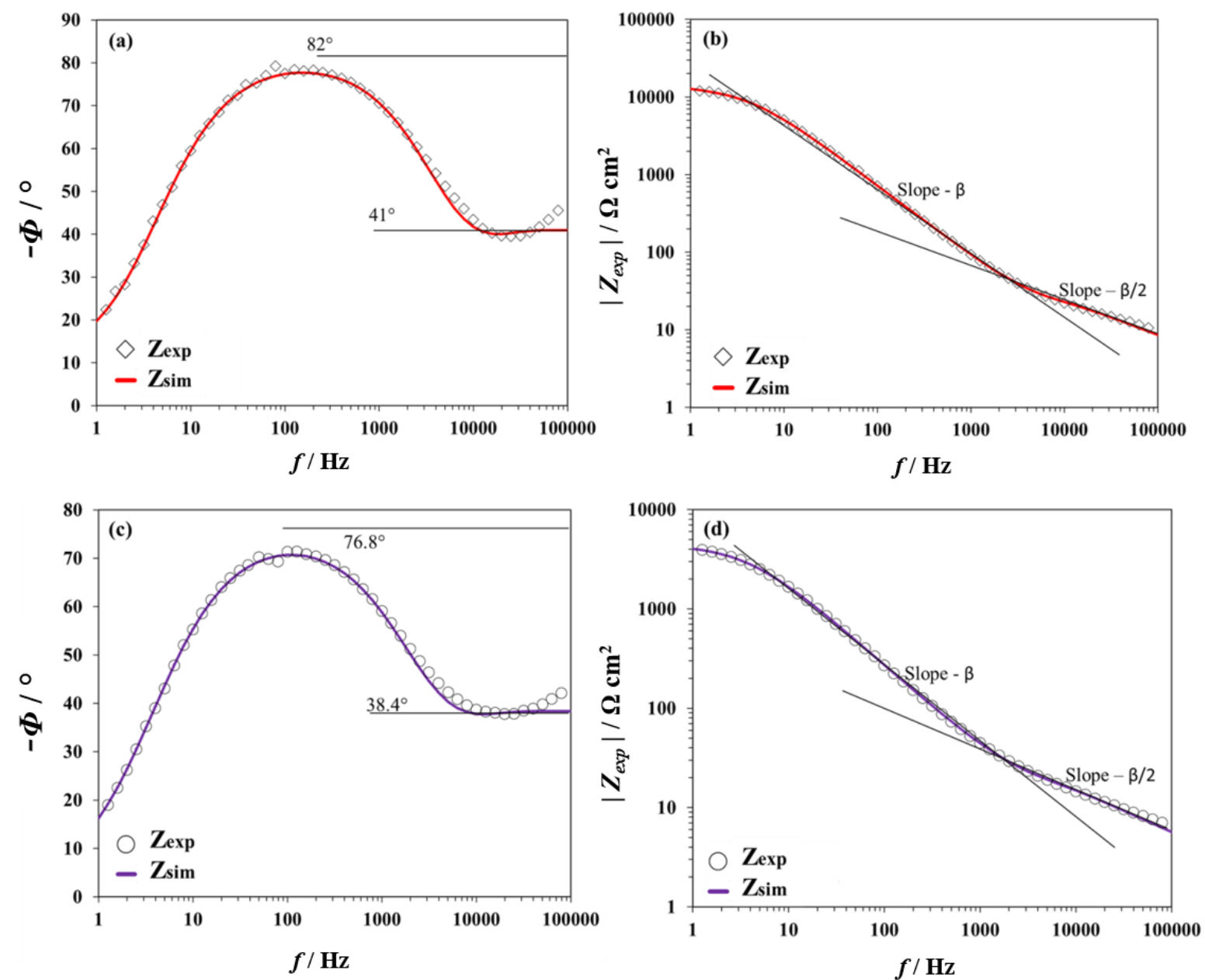

Figure 8: Fitting results for the columnar $\mathrm{ZnO}$ using Model 2 (with $C_{\mathrm{ZnO}}<<C_{d l}$ ). Re-corrected Bode plots obtained at $-0.4 \mathrm{~V}$ : (a) phase and (b) modulus. Re-corrected Bode plots obtained at $-0.5 \mathrm{~V}$ : (c) phase and (d) modulus. The open symbols represent the experimental data $\left(Z_{\text {exp }}\right)$ and the solid lines the simulated data $\left(Z_{\text {sim }}\right)$.

Table 2: Results of the fitting process for the columnar $\mathrm{ZnO}$ layers (Fig. 8) using Model 2 with $C_{\mathrm{ZnO}}<<C_{d l}$.

\begin{tabular}{|c|c|c|c|c|c|c|c|c|}
\hline $\begin{array}{c}E \\
(\mathrm{~V})\end{array}$ & $\begin{array}{c}R_{e} \\
\left(\Omega \mathrm{cm}^{2}\right)\end{array}$ & $\begin{array}{c}R_{c t} \\
\left(\Omega \mathrm{cm}^{2}\right)\end{array}$ & $\begin{array}{c}R_{0} / n^{2} \\
\left(\Omega \mathrm{cm}^{3}\right)\end{array}$ & $\begin{array}{c}R_{l} \\
(\Omega \mathrm{cm})\end{array}$ & $\begin{array}{c}Q_{\text {pore }} \\
\left(\Omega^{-1} \mathrm{~cm}^{-2} \mathrm{~s}^{\beta}\right)\end{array}$ & $\beta$ & $\begin{array}{c}Q_{Z n O} \\
\left(\Omega^{-1} \mathrm{~cm}^{-2} \mathrm{~s}^{\beta}\right)\end{array}$ & $\begin{array}{c}C_{Z n O} \\
(\mu \mathrm{F} \\
\left.\mathrm{cm}^{-2}\right)\end{array}$ \\
\hline-0.4 & 13.2 & $1.410^{+4}$ & 0.21 & $1.310^{+4}$ & $1.710^{-8}$ & 0.90 & $3.910^{-6}$ & 1.46 \\
\hline-0.5 & 13.8 & $4.510^{+3}$ & 0.23 & $8.310^{+3}$ & $7.710^{-8}$ & 0.85 & $1.4610^{-5}$ & 3.3 \\
\hline
\end{tabular}


For comparison purpose, Figure 9 shows the experimental impedance of the nano-granular $\mathrm{ZnO}$ recorded at $-0.7 \mathrm{~V}$ and the fitting curves using Model 2 with $C_{\mathrm{ZnO}} \gg>C_{d l}$ (Eq. (15)). This potential was chosen since it was also selected to investigate oxygen reduction with similar films in a recent RRDE study [16].
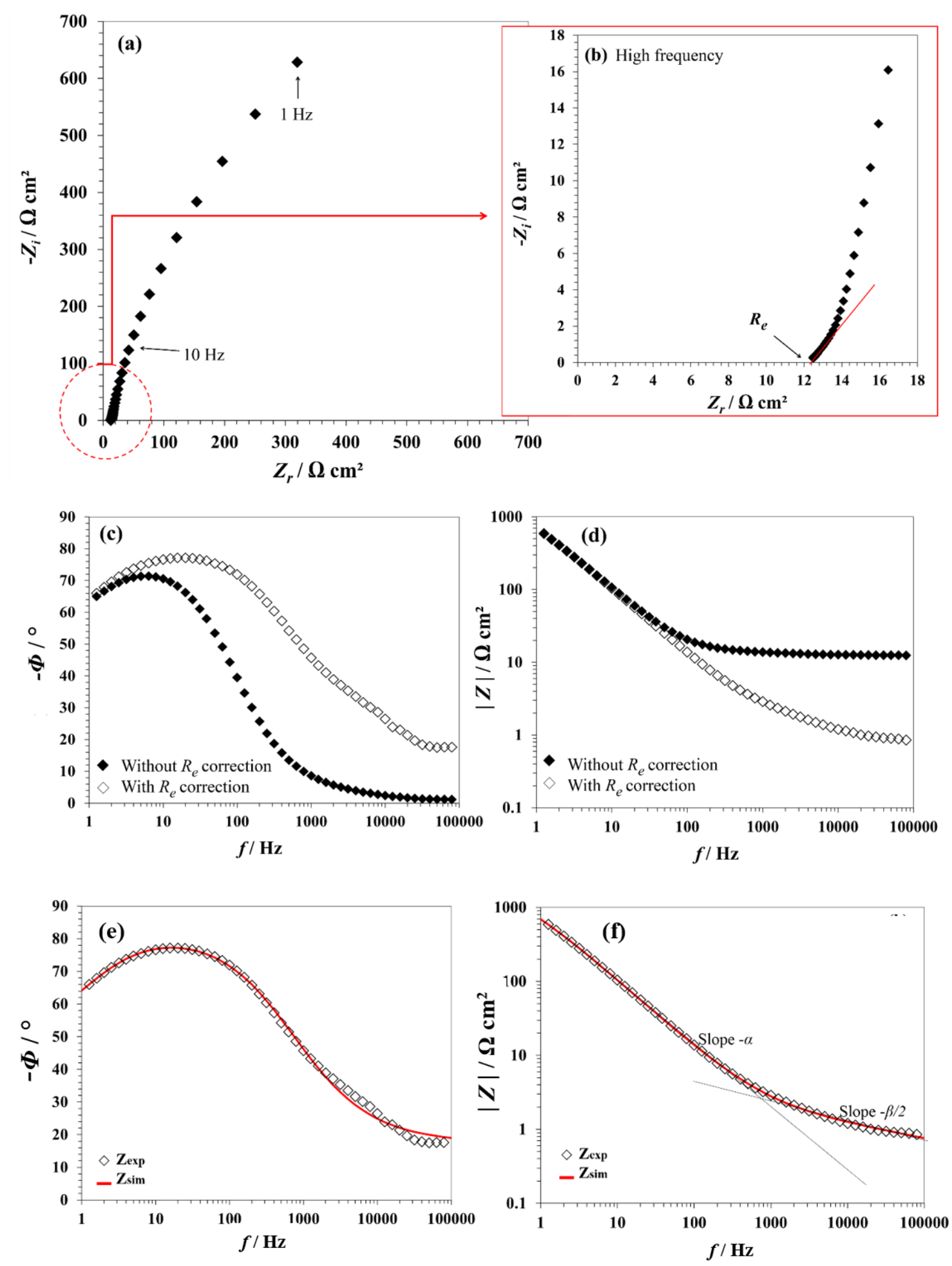

Figure 9: Typical EIS diagrams for nano-granular $\mathrm{ZnO}$ (recorded at $-0.7 \mathrm{~V}$ ). (a) Nyquist plot with (b) zoom in high frequency to determine the electrolyte resistance $\left(R_{e}\right)$. Bode plots (without and with $\mathrm{R}_{\mathrm{e}}$ 
correction): (c) phase curve and (d) modulus curve. Fitting results using Model 2 (with $C_{Z n O}>C_{d l}$ ): (e) phase curve and (f) modulus curve. The open symbols represent the experimental data $\left(Z_{\text {exp }}\right)$ and the solid lines the simulated data $\left(Z_{\text {sim }}\right)$.

$Z_{\text {sim }}$ describes $Z_{\text {exp }}$ very well in the whole frequency range. The obtained fitting parameters are listed in Table 3. The values of $C_{d l}$, that are close to their usual range of ca. $10-100 \mu \mathrm{F} / \mathrm{cm}^{2}$, confirm that $Z_{Z n O}$ is small due to its large capacitance. This is consistent with a penetration of the electrolyte in a nanoporous layer exhibiting many small pores as those observed in the ex situ HAADF-STEM analysis (Figure 2b).

Table 3: Results of the fitting process for nano-granular $\mathrm{ZnO}$ (Fig. 9e and 9f) using Model 2 with $C_{Z n O} \gg C_{d l}$.

\begin{tabular}{|c|c|c|c|c|c|c|}
\hline $\begin{array}{c}R_{e} \\
\left(\Omega \mathrm{cm}^{2}\right)\end{array}$ & $\begin{array}{c}R_{c t} \\
\left(\Omega \mathrm{cm}^{2}\right)\end{array}$ & $\begin{array}{c}Q_{l} \\
\left(\Omega^{-1} \mathrm{~cm}^{-2} \mathrm{~s}^{\beta}\right)\end{array}$ & $\beta$ & $\begin{array}{c}Q \\
\left(\Omega^{-1} \mathrm{~cm}^{-2} \mathrm{~s}^{\alpha}\right)\end{array}$ & $\alpha$ & $\begin{array}{c}C_{d l} \\
\left.(\mu \mathrm{F} \mathrm{cm})^{-2}\right)\end{array}$ \\
\hline 11.65 & 2327 & 0.028 & 0.30 & 242 & 0.89 & 120 \\
\hline
\end{tabular}

In the modulus plot (Figure 9f), the slope $-\alpha$ in low frequency range corresponds to $Z_{d l}$ (Eq. (4)) while the slope $-\beta / 2$ at high frequency relates to $Z_{Z n O}$ (Eq. (9)). The $\beta$ value is low in agreement with the small limiting phase obtained in high frequency (Figure 9e). This can be explained by a pore-in-pore model as described elsewhere in the literature [1, 38-40]. These results, along with those on columnar $\mathrm{ZnO}$, demonstrate that EIS is a powerful tool to discriminate the scale of different defects (microscale cracks vs. nanoscale pores).

Model 2 (with $C_{\mathrm{ZnO}}<<C_{d l}$ ) was also successfully applied to the columnar $\mathrm{ZnO}$ at different cathodic potentials between $-0.3 \mathrm{~V}$ and $-0.5 \mathrm{~V}$ (potentiostatic polarization). Furthermore, time-lapse EIS measurements were carried out to establish the dependence of $C_{Z n O}$ on time. The resulting $C_{Z n O}$ and $R_{c t}$ values are reported in Figure $10 . R_{c t}$ exhibits an exponential dependence on the applied potential which can be explained by the oxygen reduction kinetics being essentially limited by charge transfer (Fig. 10a). Though it is not the main focus of the study, this result stands for the physical reliability of the model and the efficiency of the fitting process.

$C_{Z n O}$ increases with increasingly negative potential (Fig. 10b) and with time (Fig. 10c). This is consistent with a potential-dependant crack propagation since, in first approximation, $C_{Z n O}$ is proportional to the defect surface in contact with the electrolyte. Post-mortem SEM analysis of 
the surfaces was carried out after polarization at $-0.4 \mathrm{~V}$ and $-0.5 \mathrm{~V}$ (Figure 11). There is no obvious sign of degradation on the $\mathrm{ZnO}$ surface after the polarization at $-0.4 \mathrm{~V}$. In contrast, Figure $11 \mathrm{~b}$ reveals significant damages after the polarization at $-0.5 \mathrm{~V}$. The propagation of the cracks goes from the surface towards the substrate till causing local delamination of the films. The propagation probably starts from the defects already present in the as-deposited state (Fig. 3a) and goes along the column boundaries.
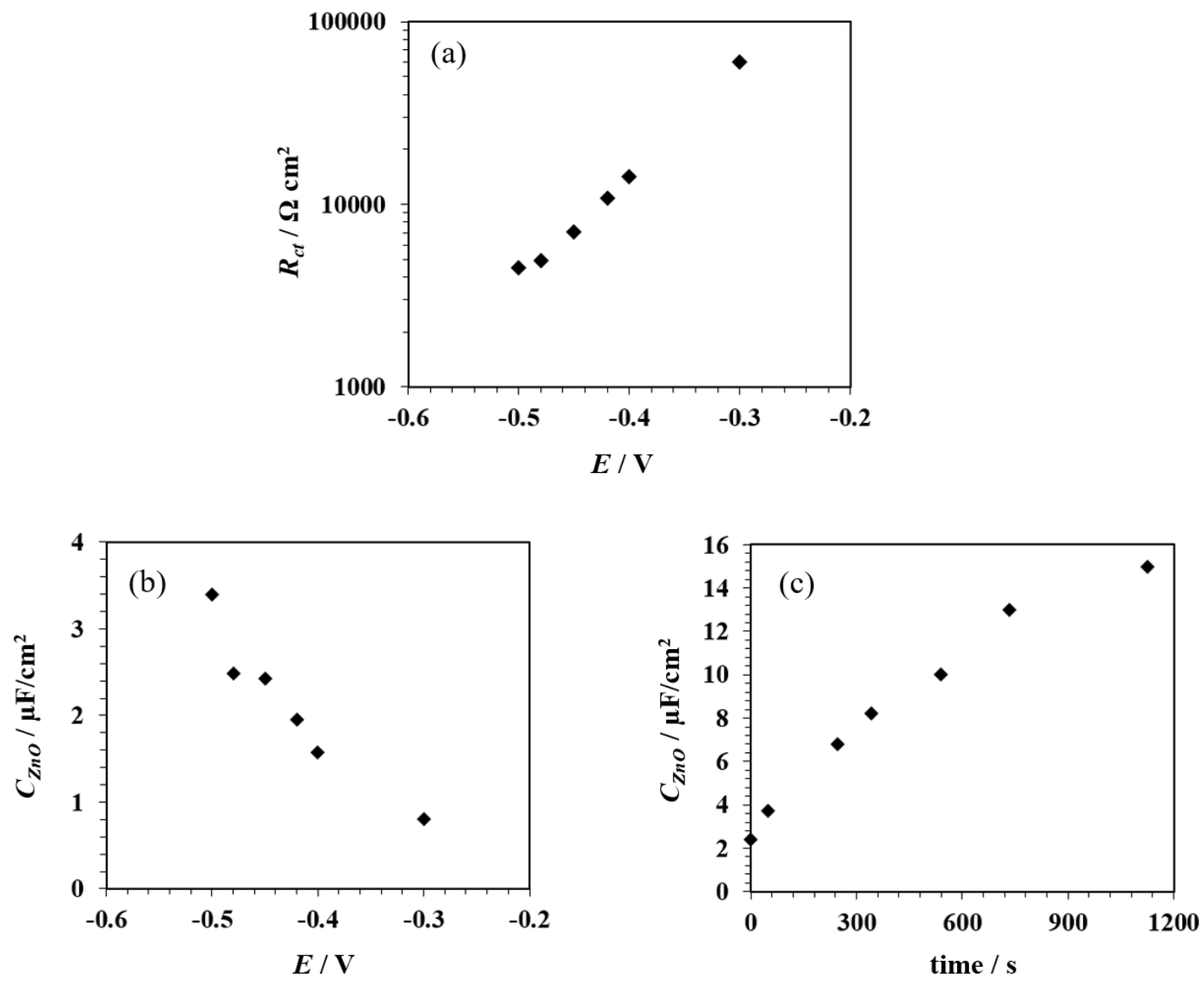

Figure 10: Application of Model 2 (with $C_{\mathrm{ZnO}}<<C_{d l}$ ) to columnar $\mathrm{ZnO}$ films polarized at different potentials $E$ : (a) $R_{c t}$ as a function of $E$; (b) $C_{Z n O}$ as a function of $E$ and (c) $C_{Z n O}$ as a function of time obtained from time-lapse EIS at $-0.5 \mathrm{~V}$.

Crack propagation is already initiated between $-0.3 \mathrm{~V}$ and $-0.4 \mathrm{~V}$ which is much lower than the film rupture potential estimated at ca. $-0.6 \mathrm{~V}$ by potentiodynamic voltammetry (Fig. 4). This is explained by the fact that, in this model, $C_{Z n O}$ is "visible" (i.e. not masked by the double layer capacitance $C_{d l}$ ) only when it has a low value, which corresponds to the first stages of degradation. The latter can go unnoticed if investigated with solely ex situ SEM top-view imaging that show only the state of the surface and not the inner walls of the cracks. This proves 
that EIS is a more sensitive technique than DC polarization curves and scanning electron microscopy to evidence the beginning of crack propagation towards the substrate.

The low values of $C_{\mathrm{ZnO}}$ also suggest that the formation of cracks is localized. EIS measurements provide only global "averaged" information over the whole surface of the $\mathrm{ZnO}$ in contact with the electrolyte. The depth, the width and the spatial distribution of the cracks cannot be assessed. A zoom-out on the micrograph of the sample polarized at $-0.5 \mathrm{~V}$ (Figure 11c) evidences that the delamination is localized in some areas (where the copper substrate is clearly visible) while other areas look damage-free. When this delamination state is reached, the model developed in this study, that characterizes the $\mathrm{ZnO} / \mathrm{electrolyte}$ interface, becomes less reliable since the copper substrate is exposed to the electrolyte and part of the stress causing the degradation has vanished.

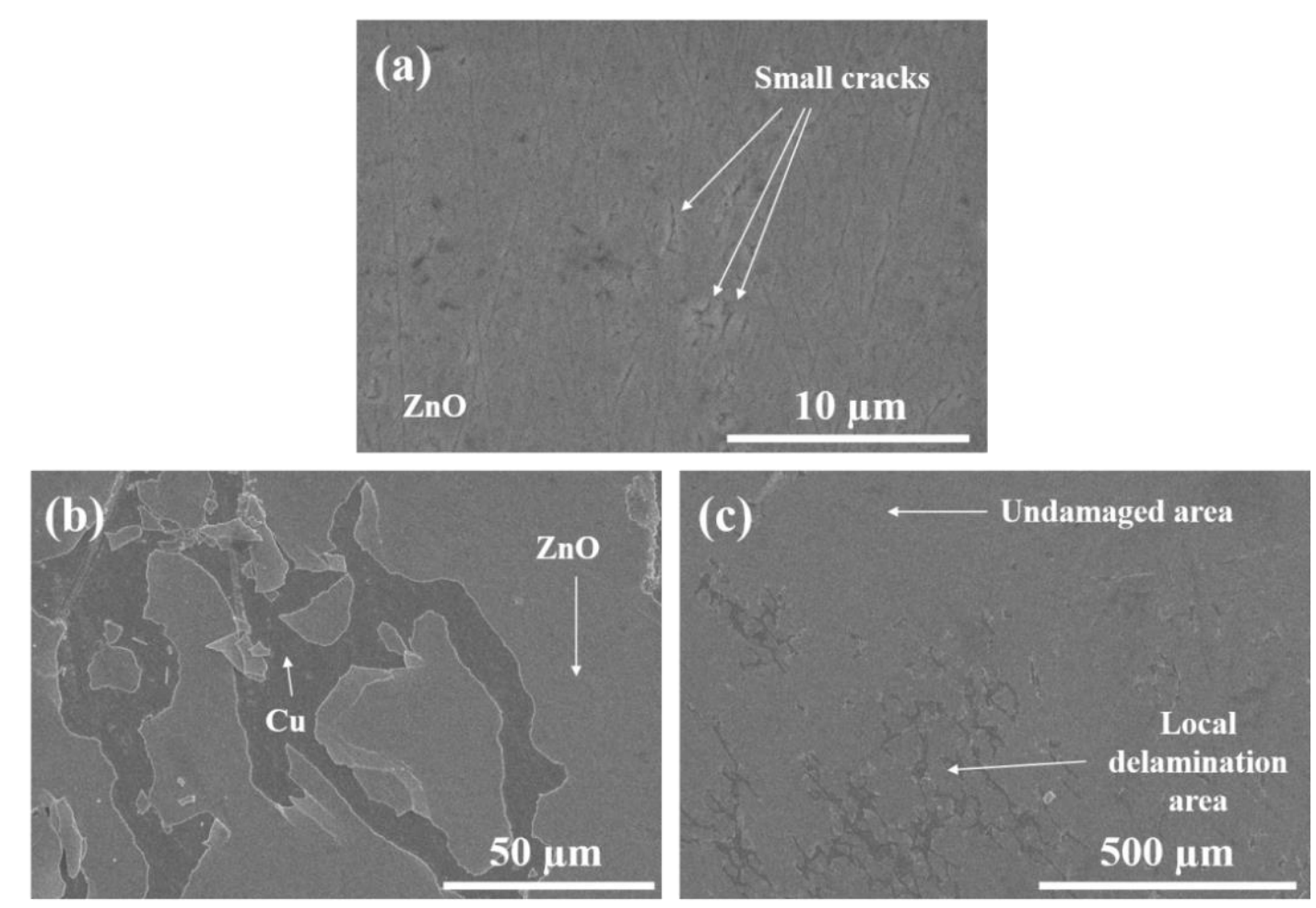

Figure 11: Post-mortem analysis of the columnar $\mathrm{ZnO}$ layers at different potentials. Top-view SEM micrographs after potentiostatic polarization at $-0.4 \mathrm{~V}$ (a) and at $-0.5 \mathrm{~V}(\mathrm{~b}, \mathrm{c})$. The copper substrate appears in darker contrast as the $\mathrm{ZnO}$ layer.

Since the film rupture clearly depends on the applied potential (Fig. 4 and Fig. 11), it can be postulated that the stress necessary to generate the cracks might originate from the piezoelectric properties of columnar $\mathrm{ZnO}$ [41-43]. The smooth dependence of $C_{\mathrm{ZnO}}$ on the applied potential 
(Figure 10b) also hints at this hypothesis. However, in order to validate this assumption, more research work is needed, e.g. in the direction of stress measurements and modelling of thin textured oxide layers under mechanical stress $[44,45]$. Those activities are beyond the scope of the present study that aims at evidencing structural defects (and their propagation) in thin films using electrochemical methods.

Figure 12 schematically summarizes the main findings of this study on columnar $\mathrm{ZnO}$. Three scenarios are considered based on different layer structures and on their apparent capacitance, $C$, "visible" by EIS. Results on nanoporous $\mathrm{ZnO}$ are also displayed for comparison.

Figure 12a shows a fully dense structure. The latter is in accordance with the STEM analysis (Figure 2a). For such structure, Model 1 (Figure 6a) is suitable and $C$ should be in the range of usual double layer capacitance values, i.e. $10-100 \mu \mathrm{F} / \mathrm{cm}^{2}$. Yet the value of $C$ observed during EIS experiments is much lower. Hence this scenario is rejected.

Figure $12 \mathrm{~b}$ shows the same columnar layer as in Figure 12a but with numerous gaps between the columns. From the impedance viewpoint, this open nanostructure is close to that of the nano-granular $\mathrm{ZnO}$ (Figure 12d) and would yield a $C$ value around 10-100 $\mu \mathrm{F} / \mathrm{cm}^{2}$ (Model 2, $C_{Z n O} \gg C_{d l}$, Figure 12f). Virtually, this open nanostructure could have been generated by a homogenous (i.e. non-localized) crack propagation along most of the column boundaries. This scenario is not supported by the post-mortem SEM analysis (showing localized degradation, Fig. 11c) and is therefore also invalid.

Thus, the only way to explain the low and increasing capacitance value of the columnar film during polarization is the localized crack propagation (leading to microscale damages and delamination) in an originally dense structure (at the nanoscale), as shown in Figure 12c. In terms of impedance modulus, this scenario leads to the case where $C_{Z n O}<<C_{d l}$ and therefore $Z_{Z n O} \gg Z_{d l}$, as illustrated in Figure $12 \mathrm{e}$ 
(a)

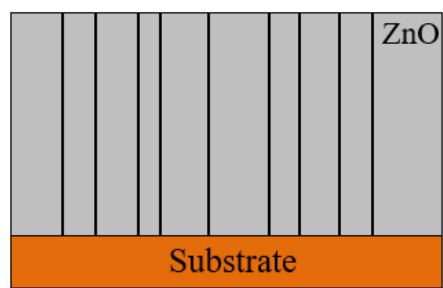

Fully dense columnar structure Model 1: $C=C_{d l}$

(c)

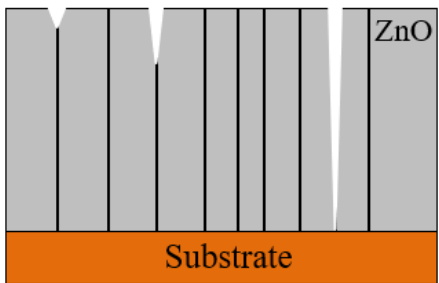

Dense structure at the nanoscale with microscaled cracks

Model 2: $C=C_{Z n O}\left(<<C_{d l}\right)$ (this study)

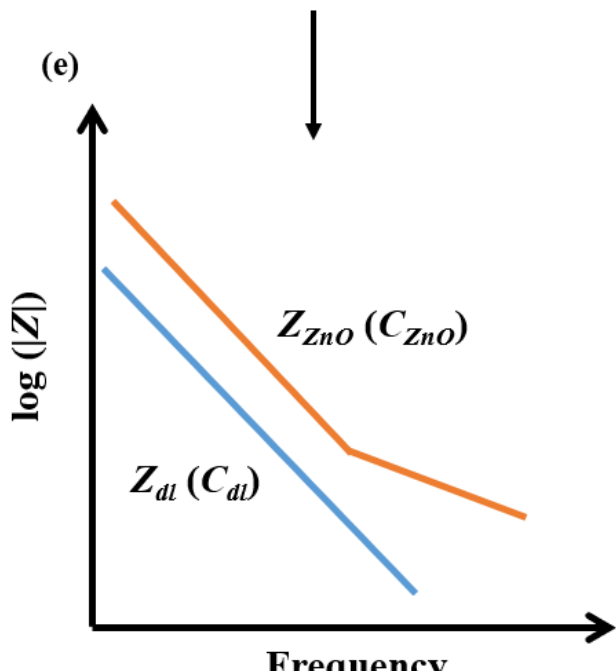

(b)

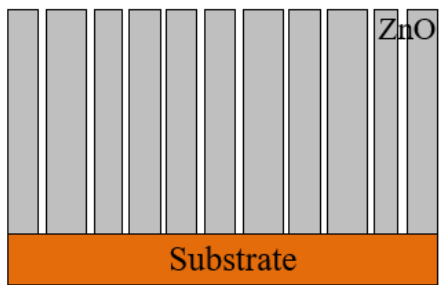

Columnar structure with gaps between the colmuns

Model 2: $C=C_{d l}\left(<<C_{Z n O}\right)$

(d)

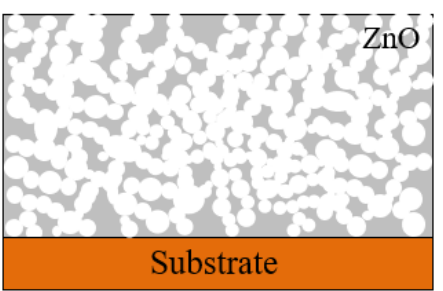

Nanoporous structure with pore/grain size $\sim 5-10 \mathrm{~nm}$ Model 2: $C=C_{d l}\left(<<C_{Z n O}\right)$ (this study)

(f)

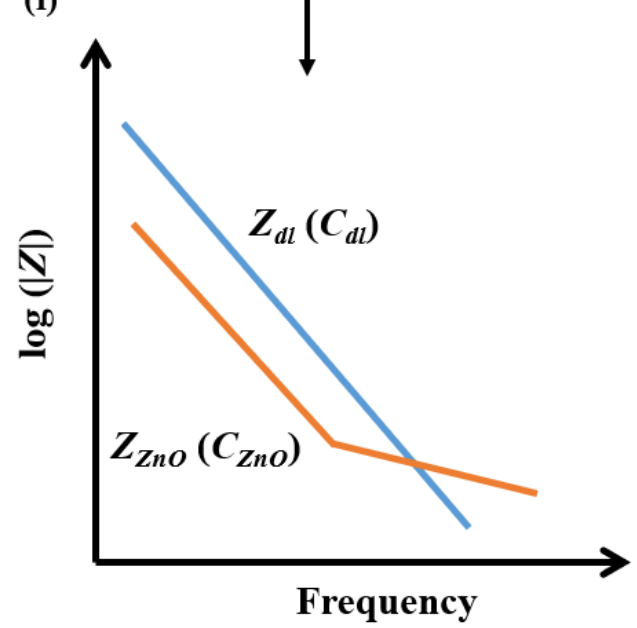

Figure 12: Schematic interpretation of the influence of the structural defects of the ZnO layers (a-d) on the impedance response (e-f) using Model 2 where $Z_{Z n O}$ and $Z_{d l}$ are in series (Figure 6b). The change of slope in the $Z_{Z n O}$ plots relates to different dependencies on the frequency (compare Eq. (6) and Eq (9)). When $C_{Z n O} \ll<C_{d l}$, (e), $Z_{Z n O}+Z_{d l} \sim Z_{Z n O}$ and solely $Z_{Z n O}$ is "visible" (measured). In contrast, when $C_{Z n O} \gg C_{d l}$, (f), $Z_{Z n O}+Z_{d l} \sim Z_{d l}$ at low frequencies (typically below $1000 \mathrm{~Hz}$ ) and $Z_{Z n O}+Z_{d l} \sim Z_{Z n O}$ at high frequencies (typically above $5000 \mathrm{~Hz}$ ). 


\section{Conclusions}

The degradation of columnar $\mathrm{ZnO}$ layers under cathodic polarization was investigated by EIS and electron microscopy. It was found that the structure of the as-deposited films was dense at the nanoscale with no gaps between the columns. An equivalent circuit model including a de Levie impedance was developed to account for the pores and cracks of the layers. The model took advantage of the flexibility of the de Levie impedance that can describe "real" electrodes whose microstructures are far from an ideal array of identical cylindrical pores developed in the initial theory. The propagation of cracks in the $\mathrm{ZnO}$ layers generates a capacitance $\left(C_{\mathrm{ZnO}}\right)$ that is approximated to be proportional to the crack inner surface in contact with the electrolyte. Due to its localized nature, $C_{Z n O}$ is sufficiently small so that its impedance is not masked by that of the double layer capacitance existing at the top of the $\mathrm{ZnO}$ surface. This stands in contrast with homogeneously distributed defects, like those of a nanoscaled pore network, that yield large $C_{Z n O}$ values. Therefore, in this case study on sputtered layers, EIS proved to be an efficient tool to unambiguously distinguish structural defects of different scales (microscaled vs. nanoscaled) and to evidence the early stages of degradation of a conductive coating.

\section{Acknowledgements}

The financial support by the Association Nationale de la Recherche et de la Technologie (ANRT, Paris, France, contract CIFRE n 2016/0066) is gratefully acknowledged. This work was also supported by the European Union through the European Regional Development Fund (ERDF), the Ministry of Higher Education and Research, the Région Bretagne, the Conseil Général du Finistère and Brest Métropole Océane, through the CPER Project 2015-2020 MATECOM. The authors thank Luiz F.G. Morales and Christian Zaubitzer (ScopeM, ETH Zurich) for technical support with HAADF-STEM experiments.

\section{References}

[1] M. E. Orazem, B. Tribollet, Electrochemical Impedance Spectroscopy, John Wiley \& Sons, $2^{\text {nd }}$ ed., 2017.

[2] T. Barres, B. Tribollet, O. Stephan, H. Montigaud, M. Boinet, Y. Cohin, Electrochim. Acta 2017, 227, 1.

[3] L. Young, Trans. Faraday Soc. 1955, 51, 1250. 
[4] B. Hirschorn, M. Orazem, B. Tribollet, V. Vivier, I. Frateur, M. Musiani, J. Electrochem. Soc. 2010, 157, C452.

[5] R. de Levie, Electrochemical response of porous and rough electrodes, Adv. Electrochem. Eng. 1967, 6, 329.

[6] O. E. Barcia, E. D. Elia, I. Frateur, O. R. Mattos, N. Pébère, B. Tribollet, Electrochim. Acta 2002, 47, 2109.

[7] Lasia, J. Electroanal. Chem. 1995, 397, 27.

[8] C. Hitz, A. Lasia, J. Electroanal. Chem. 2001, 500, 213.

[9] J.-P. Candy, P. Fouilloux, M. Keddam, H. Takenouti, Electrochim. Acta 1982, 27, 1585.

[10] W. Gao, Z. Li, Ceram. Internat. 2004, 30, 1155.

[11] M. A. Borysiewicz, E. Dynowska, V. Kolkovsky, M. Wielgus, K. Golaszewska, E. Kaminska, M. Ekielski, P. Struk, T. Pustelny, A. Piotrowska, Mater. Res. Soc. Symp. Proc. 2013, 1494, 71 .

[12] Z. Onuk, N. Rujisamphan, R. Murray, M. Bah, M. Tomakin, S. I. Shah, Appl. Surf. Sci. 2017, 396, 1458.

[13] I. Sayago, M. Aleixandre, L. Arés, M. J. Fernández, J. P. Santos, J. Gutiérrez, M. C. Horrillo, Appl. Surf. Sci. 2005, 245, 273.

[14] M. Prestat, J. Soares Costa, B. Lescop, S. Rioual, L. Holzer, D. Thierry, ChemElectroChem 2018, 5, 1203.

[15] M. Prestat, L. Holzer, B. Lescop, S. Rioual, C. Zaubitzer, E. Diler, D. Thierry, Electrochem. Commun. 2017, 81, 56.

[16] J. Soares Costa, M. Prestat, B. Lescop, S. Rioual, B. Tribollet, L. Holzer, K. Pélissier, D. Thierry, ChemElectroChem 2019, 6, 5321.

[17] S. Thomas, I.S. Cole, N. Birbilis, J. Electrochem. Soc. 2013, 160, C59.

[18] S. Thomas, I.S. Cole, M. Sridhar, N. Birbilis, Electrochim. Acta 2013, 97, 192.

[19] S. Thomas, N. Birbilis, M.S. Venkatraman, I.S. Cole, Corros. Sci. 2013, 69, 11.

[20] M.S. Venkatraman, I.S. Cole, B. Emmanuel, Electrochim. Acta 2011, 56, 8192.

[21] M. Prestat, F. Vucko, B. Lescop, S. Rioual, F. Peltier, D. Thierry, Electrochim. Acta 2016, $218,228$.

[22] T. Prosek, A. Nazarov, U. Bexell, D. Thierry, J. Serak, Corros. Sci. 2008, 50, 2216.

[23] J. Stoulil, T. Prosek, A. Nazarov, J. Oswald, P. Kriz, D. Thierry, Mater. Corros. 2015, 66, 777.

[24] I. S. Cole, Materials 2017, 10, 1288.

[25] S.Y. Chu, W. Water, J.T. Liaw, J. Eur. Ceram. Soc. 2003, 23, 1593. 
[26] S. S. Lin, J. L. Huang, Surf. Coat. Tech. 2004, 185, 222.

[27] J. Hüpkes, J. I. Owen, S. E. Pust, E. Bunte, ChemPhysChem 2012, 13, 66.

[28] J. Han, W. Qiu, W. Gao, J. Hazard. Mater. 2010, 178, 115.

[29] Z. Onuk, N. Rujisamphan, R. Murray, M. Bah, M. Tomakin, S. I. Shah, Appl. Surf. Sci. 2017, 396, 1458.

[30] J. Sakabe, N. Ohta, T. Ohnishi, K. Mitsuishi, K. Takada, Commun. Chem. 2018, 1, art. \#24.

[31] V. Godinho, P. Moskovkin, R. Álvarez, J. Caballero-Hernández, R. Schierholz, B. Bera, J. Demarche, A. Palmero, A. Fernández, S. Lucas, Nanotechnology 2014, 25, art. \#355705.

[32] H. S. Wroblowa, S. B. Qaderi, J. Electroanal. Chem. 1990, 153, 295.

[33] N. Heller-Ling, M. Prestat, J. L. Gautier, J. F. Koenig, G. Poillerat, P. Chartier, Electrochim. Acta 1997, 42, 197.

[34] T. T. M Tran, B. Tribollet, E. M. M Sutter, Electrochim. Acta 2016, 216, 58.

[35] B. Hirschorn, M.E. Orazem, B. Tribollet, V. Vivier, I. Frateur, M. Musiani, J. Electrochem. Soc. 2010, 157, C458.

[36] M. E. Orazem, N. Pébère, B. Tribollet, J. Electrochem. Soc. 2006, 153, B129.

[37] G. J. Brug, A. L. G. Van Den Eeden, M. Sluyters-Rehbach, J. H. Sluyters, J. Electroanal. Chem. 1984, 176, 275.

[38] M. Itagaki, Y. Hatada, I. Shitanda, and K. Watanabe, Electrochim. Acta 2010, 55, 6255.

[39] Y. Gourbeyre, B. Tribollet, C. Dagbert, and L. Hyspecka, J. Electrochem. Soc. 2006, 153, B162.

[40] Y. Ben Amor, E. Sutter, H. Takenouti, M. E. Orazem, B. Tribollet, J. Electrochem. Soc. 2014, 161, C573.

[41] S.Y. Chu, W. Water, J.T. Liaw, J. Eur. Ceram. Soc. 2003, 23, 1593.

[42] K. B. Sundaram, A. Khan, Thin Solid Films 1997, $295,87$.

[43] Y. H. Hsu, J. Lin, W. C. Tang, J. Mater. Sci.: Mater. Electron. 2008, 19, 653.

[44] Y. Safa, T. Hocker, M. Prestat, A. Evans, J. Power Sources 2014, 250, 332.

[45] A. Evans, M. Prestat, R. Tölke, M.V.F. Schlupp, L.J. Gauckler, Y. Safa, T. Hocker, J. Courbat, D. Briand, N.F. de Rooij, D. Courty, Fuel Cells 2012, 12, 614. 